\title{
真盐生植物囊果碱蓬(Suaeda physophora)脱水 种子子叶叶绿素特征及其对植物萌发阶段适应 盐渍环境的生态意义
}

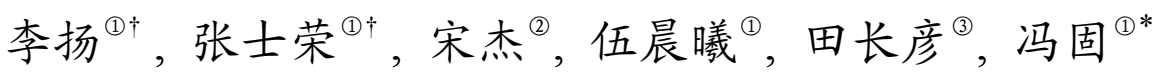
(1) 教育部植物-土壤相互作用重点开放实验室 中国农业大学资源与环境学院, 北京 100094 ;
(2) 山东师范大学生命科学学院, 济南 250014;
(3) 中国科学院新疆生态与地理研究所, 乌鲁木齐 830049
$\dagger$ 同等贡献
* 联系人, E-mail: fenggu@cau.edu.cn 项目

摘要本研究观察到囊果碱蓬(Suaeda physophora)脱水种子子叶含有深绿色色素, 分别在 645 和 $663 \mathrm{~nm}$ 波长下测定了脱水种子子叶和黑暗中在去离子水半浸没 $12 \mathrm{~h}$ 的种子子叶内色素含量及其在 400 700 nm 波长范围内的光谱吸收特征曲线, 并与囊 果碱蓬真叶内的叶绿素光吸收特征曲线进行比较, 结果显示这种色素是叶绿素, 其 光吸收特征曲线与真叶叶绿素的几乎完全相同, 表明这种叶绿素具有和真叶叶绿素 相近的生理功能. 通过光合能力测定发现, 囊果碱蓬脱水种子吸水 $6 \mathrm{~h}$ 后就能进行光 合放氧. 用电子显微镜观测了在去离子水和 $700 \mathrm{mmol} / \mathrm{L} \mathrm{NaCl}$ 溶液中处理 1 天和 10 天的襄果碱蓬种子的叶绿体形态，同时对胚根细胞质膜的受损伤程度进行了组织化 学染色观测, 并以同为黎科、且脱水种子子叶中也存在叶绿体的旱生植物白梭梭 (Haloxylon persicum) 为对照进行同步观测. 结果表明, 相对于非盐生植物白梭梭, 高 盐度下囊果碱蓬种子的子叶叶绿体结构、胚根细胞质膜均保持完好, 表现出很强的抗 盐能力. 黑暗条件下囊果碱蓬种子在去离子水和 $700 \mathrm{mmol} / \mathrm{L} \mathrm{NaCl}$ 溶液中的萌发过程 是渐进式的, 72 84 h 才能达到萌发高峰; 但是在 $700 \mathrm{mmol} / \mathrm{L} \mathrm{NaCl}$ 溶液中浸泡 10 天 而未萌发的种子移到去离子水中以后的恢复萌发则是爆发式的, 在 $24 \mathrm{~h}$ 之内即达到 萌发高峰, 并且这些种子具有光合能力. 因此可以推断, 高浓度的盐分对于真盐生植 物囊果碱蓬的快速恢复萌发具有激发效应, 这种特性保证了种子在自然条件下能够 在早春短暂的、适宜的土壤低盐分条件下迅速萌发; 千燥种子子叶中保留的具有完整 结构的叶绿体则可通过光合作用保证萌发了的幼苗迅速生长, 建立种群.
关键词

真盐生植物

囊果碱蓬

脱水种子子叶

叶绿素

萌发 
种子是植物的繁殖体，植物群落的形成、种群过 程(如定居、扩散)和演替均与种子萌发特性有关 ${ }^{[1,2]}$. 种子萌发阶段是植物生活周期中对土壤盐度最敏感 的阶段 ${ }^{[3,4]}$, 盐分的渗透胁迫与离子毒害导致种子渗 透势降低或者膜受损，进而使萌发率降低 ${ }^{[5 \sim 7]}$. 在春 季, 干旱区盐渍土壤的盐分含量、水分含量和温度变 化剧烈. 融化的雪水和春雨可以降低表层土壤的盐 分浓度 ${ }^{[8]}$, 而气温的快速回升又会使得土壤水分迅速 蒸发，使表层土壤中盐分浓度快速回升 [9]. 因此，在 高盐度下盐生植物种子的萌发能力和幼苗早期的快 速生长能力是决定其是否能成功地在盐渍环境中定 居和建成种群的关键因素. 盐生植物种子可以通过 多种途径抵抗盐的危害, 在高盐度条件下保持种子 活力. 例如利用种皮进行盐离子区隔化 ${ }^{[10]}$; 盐生植 物种子在高盐度条件下休眠，当土壤盐分被水淋洗 而降低后迅速恢复萌发 ${ }^{[11]}$ 等.

囊果碱蓬(Suaeda physophora)属僽科, 螺胚亚科, 碱蓬属的叶肉质化的半灌木 ${ }^{[12]}$, 属于真盐生植物, 广泛生长于中亚荒漠地区，是新疆准噶尔盆地的常 见种 ${ }^{[13]}$. 对干旱区的绿化、防风固沙起到重要作用, 其幼苗还可以入食, 并具有一定的药用价值 ${ }^{[13]}$. 前 人对于这种植物的研究主要集中在其适应极端盐渍 环境的渗透调节特性 ${ }^{[10]}$ 、种子连续萌发策略 ${ }^{[14]}$ 以及 温度、盐分和光照等条件对该植物种子萌发的影响 [15]. 宋杰 [10]观察到囊果碱蓬脱水种子子叶呈深绿色, 推测这种色素可能是叶绿素. 然而通常情况下, 叶绿 素的合成是受光诱导的 ${ }^{[16]}$; 虽然许多植物的子房或 胚珠在母体上发育成种皮或胚的过程中也会合成叶 绿素，但是当种子成熟、脱水干燥后子叶、种皮或者 果皮上的这些叶绿素也会随之消失 ${ }^{[16]}$. 也有研究观 察到在一些植物的脱水种子胚含有叶绿素, 如莲 (Nelumbo- nucifera Gaertn) ${ }^{[17]}$ 和红桔(Citrus reticulata Blanco $)^{[18]}$ 等, 但对生长在极端环境中的真盐生植物 的脱水种子肧含有叶绿素的现象鲜见报道. 因此, 我 们观察到的囊果碱蓬脱水种子子叶内的色素是不是 叶绿素? 如果是的话这些叶绿素的理化特性与叶片 叶绿素是否相同? 这些叶绿素对囊果碱蓬早期生长 有什么作用? 对于这些问题目前还缺乏了解. 本研 究测定了囊果碱蓬脱水种子子叶内色素的含量、理化 特性及叶绿体结构对盐分的反应, 并对种子叶绿素
在植物适应极端盐渍环境的作用进行了讨论，以期 为理解植物适应盐渍环境的生理生态机制提供依据.

\section{1 材料与方法}

\section{1 实验材料}

囊果碱蓬(Suaeda physopora)种子供试材料 2005 年 10 月采自新疆八一水库东侧 200 米(N44 $13.107^{\prime}$, $\mathrm{E} 87^{\circ} 41.052^{\prime}$ ), 白梭梭(Haloxylon persicum)种子供试 材料 2005 年 10 月采自新疆古尔班通古特沙漠南缘 $\left(\mathrm{N} 44^{\circ} 22.019^{\prime}, \mathrm{E} 87^{\circ} 55.021^{\prime}\right)$, 采回的种子在室内风干 后放在 $-10^{\circ} \mathrm{C}$ 冰柜中保存.

\section{2 实验方法}

（1）囊果碱蓬种子和胚形态结构的观察: 随机抽 取一定量的囊果碱蓬干种子观察其外形, 测量千粒 重和容重, 均重复 4 次得平均值和标准差. 取若干粒 种子用去离子水在黑暗 $20^{\circ} \mathrm{C}$ 条件下处理 $12 \mathrm{~h}$, 然后 小心剥去种皮，避免损伤胚. 用实体显微镜(XTL30, 北京太科精密设备有限公司, 北京)对完整干种子、去 皮的干种子胚以及去离子水处理 $12 \mathrm{~h}$ 的种子的裸胚 进行观察拍照.

(2) 囊果碱蓬种子子叶内叶绿素含量的测定: 分 别取囊果碱蓬脱水干种子、黑暗条件下在去离子水中 处理了 $12 \mathrm{~h}$ 的种子、黑暗条件下在 $700 \mathrm{mmol} / \mathrm{L} \mathrm{NaCl}$ 溶液中处理了 10 天的种子子叶及在Hoagland营养液 中培养了 30 天的囊果碱蓬幼苗真叶. 按文献 [19]的 方法, 以 $80 \%$ 丙酮为提取剂,采用日本岛津-UV2201 型分光光度计测定色素在波长 645 和 $663 \mathrm{~nm}$ 处的吸 收值, 计算总叶绿素含量、叶绿素 $\mathrm{a}$ 和叶绿素 $\mathrm{b}$ 的含量 以及叶绿素 $\mathrm{a} / \mathrm{b}$ 比值.

(3) 种子子叶与真叶内叶绿素吸收光谱特性的测 定: 将囊果碱蓬种子播种于装有石英沙(稀盐酸洗过) 的塑料花盆中, 于光照培养室内育苗. 幼苗每天浇以 营养液, 营养液中含有: $0.05 \mathrm{mmol} / \mathrm{L} \mathrm{Ca}\left(\mathrm{NO}_{3}\right)_{2}, 3$ $\mathrm{mmol} / \mathrm{L} \mathrm{CaCl}_{2}, 1 \mathrm{mmol} / \mathrm{L} \mathrm{K}_{2} \mathrm{SO}_{4}, 2 \mathrm{mmol} / \mathrm{L} \mathrm{MgSO}_{4}, 1$ $\mathrm{mmol} / \mathrm{L} \mathrm{KH}_{2} \mathrm{PO}_{4}, 1 \mathrm{mmol} / \mathrm{L} \mathrm{NaCl}$. 营养液中的 $\mathrm{Fe}^{2+}$ 和 微量元素含量与完全 Hoagland 营养液相同. 溶液 $\mathrm{pH}$ 用 $\mathrm{KOH}$ 和 $\mathrm{H}_{2} \mathrm{SO}_{4}$ 调至 $6.5 \pm 0.1$.

取培养 30 天的囊果碱蓬叶片和黑暗条件下在去 离子水中处理了 $12 \mathrm{~h}$ 的囊果碱蓬种子子叶提取叶绿 
素，提取方法同 1.2 实验方法(2)，以 $20 \mathrm{~nm}$ 波长为间 隔，采用日本岛津-UV2201 型分光光度计测定 400 $700 \mathrm{~nm}$ 波长范围内叶绿素的光吸收特征曲线.

(4) $\mathrm{NaCl}$ 处理对囊果碱蓬种子光合作用能力的影 响: 将囊果碱蓬种子约 200 颗置于铺有两层滤纸的培 养血中，用 $20 \mathrm{~mL}$ 去离子水和 $700 \mathrm{mmol} / \mathrm{L} \mathrm{NaCl}$ 溶液 在持续黑暗 $20^{\circ} \mathrm{C}$ 条件下处理 0,6 和 $24 \mathrm{~h}$, 在 $25^{\circ} \mathrm{C}$, 光 强 $500 \mu \mathrm{mol} / \mathrm{m}^{2} \cdot \mathrm{s}$ 的条件下用 Hansatech Oxygraph System 液相氧电极(Hansatech Instruments Ltd., UK) 测定光合放氧特征值. 每次剪取 10 颗种子的子叶进 行测定, 重复 3 次.

(5) $\mathrm{NaCl}$ 处理对囊果碱蓬种子萌发率、恢复率和 总萌发率的影响: (i) 萌发率测定: 分别将 150 粒种子 半浸没在装有 $20 \mathrm{~mL} 700 \mathrm{mmol} / \mathrm{L} \mathrm{NaCl}$ 溶液的培养 皿中, 将培养血先放在一个纸盒之中, 纸盒外部用不 透光的牛皮纸包裹. 从第二天开始, 在暗室背光条件 下每天将盐溶液完全更换掉，以胈根露出 $2 \mathrm{~mm}$ 为萌 发的标准把已萌发的种子拣出, 并且记录每天萌发 的种子数. 重复 4 次. (ii) 恢复率测定: 10 天后从每 个重复未萌发的种子中挑出 50 粒未萌发的种子用去 离子水漂洗 3 次, 立即转移到装有 $10 \mathrm{~mL}$ 去离子水、 铺有两层滤纸的培养皿中. 采用相同的避光方式每 天记录萌发的种子数, 共观测 8 天, 至种子萌发率连 续 3 天不再增加为止. 同时做对照处理, 即: 取未经 $700 \mathrm{mmol} / \mathrm{L} \mathrm{NaCl}$ 溶液处理的干种子 4 份, 每份 50 粒，在同样的条件下观测 8 天，每天记录萌发的种子 数. 总萌发率按以下公式计算:

$$
(b+(a-b) / 50 \times c) / a \times 100 \%,
$$

式中 $a$ 为总种子数, $b$ 为在盐溶液中萌发的种子数, $c$ 为在盐溶液中未萌发的种子 (50 粒) 转入去离子 水中后恢复萌发的种子数.

(6) $\mathrm{NaCl}$ 胁迫下囊果碱蓬种子子叶叶绿体形态结 构、胚根细胞质膜完整性的观察：分别取 $20^{\circ} \mathrm{C}$ 黑暗 条件下在去离子水处理 1 天和 $700 \mathrm{mmol} / \mathrm{L} \mathrm{NaCl}$ 溶液 处理 10 天的未萌发的囊果碱蓬的种子, 剥去种皮, 用戊二醛固定液固定 $24 \mathrm{~h}, 1 \%$ 锇酸中固定 $4 \mathrm{~h}$, 系列 浓度丙酮脱水, Spurr树脂包埋, 瑞典LKBIII 型超薄 切片机切片, 醋酸双氧铀和柠檬酸铅双重染色, 并利 用日本JEM-1010 电子显微镜观察子叶内叶绿体形态 结构并拍照. (为了与非盐生植物做比较, 取同属黎科
的、种子结构形态类似的、子叶也存在叶绿体的旱生 植物白梭梭 ${ }^{[10]}$ 的种子作为对照).

从每个重复中随机选取一定量的未萌发的种子, 放入 $2 \mathrm{~mL} 0.5 \%(\mathrm{~W} / \mathrm{V})$ 的Evan's blue染料(Sigma)溶液, $10 \mathrm{~min}$ 后用去离子水冲洗 3 次, 在实体显微镜(XTL3, 北京太科精密设备有限公司)下观察并照相 [20]. (为了 与非盐生植物做比较, 仍以旱生植物白梭梭作为对 照).

\section{3 数据统计分析}

萌发率数据经过反正弦转换. 所有数据均用统 计分析软件 SAS 的 ANOVA 过程进行方差分析, 用 LSD 法进行多重比较.

\section{2 结果分析}

\section{1 囊果碱蓬种子形态与物理特征}

随机抽取囊果碱蓬种子, 测定其千粒重为(1.40土 $0.01) \mathrm{g}$ (数据为平均值 $\pm \mathrm{SD}, n=4)$; 容重为 $(4.39 \pm 0.01)$ $\mathrm{g} / \mathrm{L}$ (数据为平均值 $\pm \mathrm{SD}, n=4$ ); 调查中观测到种胚有 左旋和右旋两种结构, 且左旋和右旋种子各约占一 半, 二者的比例为 $0.95 \pm 0.16$ (数据为平均值 $\pm \mathrm{SD}, n=4$ ). 图 1(a)为囊果碱蓬带着种皮的干种子的形态; 图 1(b) 是干种子去除种皮后的胚的形态, 中部暗绿色的螺 旋组织是含有色素的子叶, 外围呈现浅红色的组织 是胚根. 图 $1(\mathrm{c})$ 为在 $20^{\circ} \mathrm{C}$ 持续黑暗条件下去离子水处 理 $12 \mathrm{~h}$ 后胚的结构. 可以看出, 囊果碱蓬种子没有胚 乳, 胚呈螺旋状, 胚根和胚轴在螺旋形的子叶外侧, 子叶在螺旋的内侧. 种子吸收水分以后子叶由暗绿 色转变为绿色, 胚根呈乳白.

\section{2 囊果碱蓬种子子叶内叶绿素的含量}

囊果碱蓬脱水干种子和 $20^{\circ} \mathrm{C}$ 持续黑暗条件下用 去离子水处理 $12 \mathrm{~h}$ 后的种子都提取到了叶绿素, 并 且子叶叶绿素 $\mathrm{a}$ 与叶绿素 $\mathrm{b}$ 含量比均为 3 左右(表 1). 黑暗条件下 $700 \mathrm{mmol} / \mathrm{L} \mathrm{NaCl}$ 处理 10 天后的种子子 叶叶绿素含量与去离子水中处理 $12 \mathrm{~h}$ 后的子叶的叶 绿素含量没有显著差别.

\section{3 囊果碱蓬种子子叶与真叶叶绿素的光吸收特 征曲线}

图 2 显示了囊果碱蓬种子在 $20^{\circ} \mathrm{C}$ 去离子水中持 


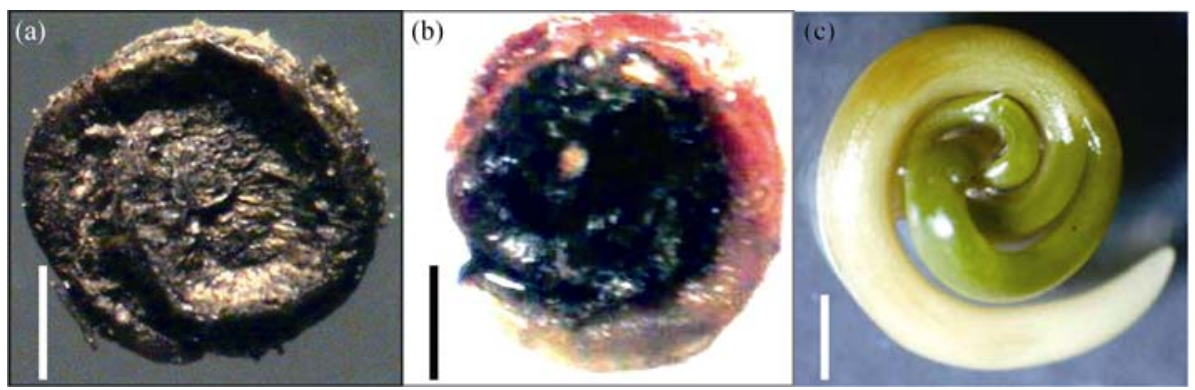

图 1 囊果碱蓬的种子形态

(a)末去除种皮的干种子; (b)去除种皮后的干种子胚; (c)在 $20^{\circ} \mathrm{C}$ 持续黑暗条件下去离子水中处理 $12 \mathrm{~h}$ 后胚的结构. 标尺表示 $1 \mathrm{~mm}$

表 1 囊果碱蓬干种子在 $20^{\circ} \mathrm{C}$ 去离子水中处理 $12 \mathrm{~h}$ 和在 $700 \mathrm{mmol} / \mathrm{L} \mathrm{NaCl}$ 处理 10 天后子叶中叶绿素含量 ${ }^{\text {a) }}$

\begin{tabular}{cccc}
\hline 种子 & 叶绿素 $\mathrm{a}\left(\mathrm{mg} \cdot \mathrm{g}^{-1} \mathrm{DW}\right)$ & 叶绿素 $\mathrm{b}\left(\mathrm{mg} \cdot \mathrm{g}^{-1} \mathrm{DW}\right)$ & 叶绿素 $(\mathrm{a}+\mathrm{b})\left(\mathrm{mg} \cdot \mathrm{g}^{-1} \mathrm{DW}\right)$ \\
\hline 干种子 & $0.67 \pm 0.06$ & $0.23 \pm 0.03$ & $0.90 \pm 0.03$ \\
子叶 $\left(0 \mathrm{mmol} \cdot \mathrm{L}^{-1} \mathrm{NaCl}\right)$ & $1.24 \pm 0.03$ & $0.34 \pm 0.02$ & $1.58 \pm 0.05$ \\
子叶 $\left(700 \mathrm{mmol} \cdot \mathrm{L}^{-1} \mathrm{NaCl}\right)$ & $1.23 \pm 0.02$ & $0.37 \pm 0.03$ & $1.60 \pm 0.04$ \\
\hline
\end{tabular}

a) 数据为平均值 $\pm \mathrm{SE}, n=3 ; \mathrm{DW}$ 代表干物质的量

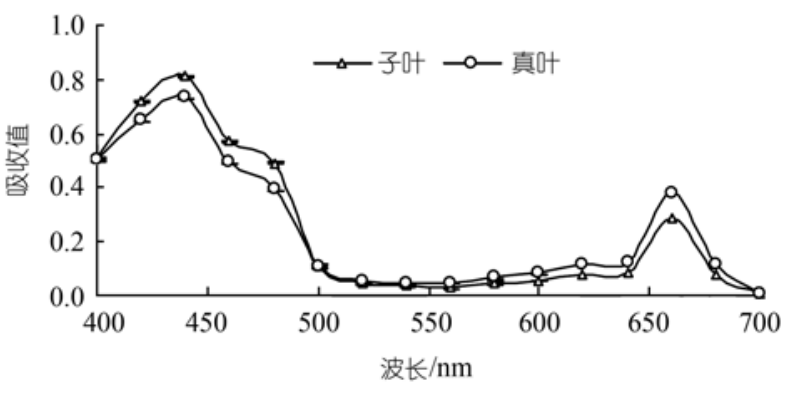

图 $220^{\circ} \mathrm{C}$ 去离子水中黑暗条件下持续处理 $12 \mathrm{~h}$ 的囊果碱 蓬种子子叶与培养 30 天的幼苗真叶叶绿素在 400 700 nm 范围内的光吸收特征曲线

图中每点为 3 次重复的平均值

续黑暗条件下处理 $12 \mathrm{~h}$ 后其种子子叶和生长到第 30 天时幼苗的真叶的叶绿素光吸收特征曲线. 如图所 示, 在 400 700 $\mathrm{nm}$ 的波长范围内囊果碱蓬真叶内叶 绿素有两个吸收峰，分别位于红光区 $670 \mathrm{~nm}$ 附近、 蓝光区 $445 \mathrm{~nm}$ 附近; 囊果碱蓬脱水种子子叶叶绿素 与真叶的叶绿素具有几乎相同的吸光特性, 子叶叶 绿素的吸收曲线无论在变化趋势还是在具体的吸收 峰值及其对应的波长都几乎与真叶内叶绿素一致.

\section{$2.4700 \mathrm{mmol} / \mathrm{L} \mathrm{NaCl}$ 处理下种子子叶的光合放} 氧特征

表 2 为去离子水和 $700 \mathrm{mmol} / \mathrm{L} \mathrm{NaCl}$ 处理 0,6 和
$24 \mathrm{~h}$ 后囊果碱蓬种子子叶的光合放氧特征. 从表中可 以看到, 在种子萌发阶段, 干种子无论是放入去离子 水还是 $700 \mathrm{mmol} / \mathrm{L} \mathrm{NaCl}$ 中，均不能立刻检测到光合 作用; 而在去离子水或者盐溶液中浸泡 6 和 $24 \mathrm{~h}$ 以后, 子叶可进行光合作用并放出氧气, 且种子子叶放氧 速率在去离子水处理和 $700 \mathrm{mmol} / \mathrm{L} \mathrm{NaCl}$ 处理之间没 有显著差别. 将 $700 \mathrm{mmol} / \mathrm{L} \mathrm{NaCl}$ 溶液中处理 10 天 而未萌发的种子取出, 移入去离子水中 $0,24 \mathrm{~h}$ (已萌 发)后的囊果碱蓬种子也测到了光合放氧现象(表 2).

上述结果表明, 干燥的囊果碱蓬种子不能进行光 合作用，但当种子吸收水分以后则能够很快开始进行 光合作用，且种子的光合系统对盐有较高的耐性.

\section{$2.5 \mathrm{NaCl}$ 处理 10 天对囊果碱蓬种子子叶叶绿体 超微结构的影响}

透射电子显微镜观察的结果, 如图 3 所示. 囊果 碱蓬种子在去离子水中处理 1 天后，子叶叶肉细胞内 清哳可见均匀分布着近似椭圆形的叶绿体. 叶绿体 内有许多扁平小囊，即类囊体，绝大部分为基粒类囊 体, 垛叠层数较多, 基粒数目也较多, 排列整齐, 形 成一个完整连续的类囊体膜囊(图 3(a)，(b)). 白梭梭种 子在去离子水中处理 1 天后的子叶的叶肉细胞内的叶 绿体也观察到与囊果碱蓬相似的结果(图 3(c), (d)). 
囊果碱蓬种子在 $700 \mathrm{mmol} / \mathrm{L} \mathrm{NaCl}$ 中处理 10 天 后的种子子叶叶肉细胞内可见基质类囊体与基粒类 囊体开始分化，构成基粒的垛叠层数仍较多，基粒数 目也较多，且排列整齐. 两个或两个以上的基粒类囊 体仍然由基质类囊体相连通，构成一个完整连续的 封闭膜囊(图 3(b)) . 然而, 白梭梭种子子叶叶肉细胞 内的叶绿体在 $700 \mathrm{mmol} / \mathrm{L} \mathrm{NaCl}$ 中处理 10 天后类囊 体排列紊乱, 类囊体片层解体(图 3(d)). 这表明即使 在 $700 \mathrm{mmol} / \mathrm{L} \mathrm{NaCl}$ 高浓度盐胁迫下, 真盐生植物囊 果碱蓬种子的子叶叶绿体结构仍然保持完好, 反映 出其超强的抗盐能力.
2.6 去离子水处理 1 天和 $\mathrm{NaCl}$ 处理 10 天的囊果 碱蓬种子胚 Evan' s blue 染料( $\mathrm{Mr}=960$;Sigma) 试 剂染色

Evan's blue 染料 $(M r=960 ;$ Sigma)试剂只染色死 细胞，这种染色方法可以检验细胞膜完整性是否受到 破坏，凡是受到伤害的细胞质膜都会被染上蓝色 ${ }^{[21 ~ 23]}$. 从图 4 的结果可见, 囊果碱蓬种子在 $700 \mathrm{mmol} / \mathrm{L} \mathrm{NaCl}$ 中处理后胚根的Evan's blue 染料(Sigma)染色结果 (图 4(a)中 2)与对照(图 4(a)中 1)没有差别; 非盐生植 物白梭梭的种子经过 $700 \mathrm{mmol} / \mathrm{L} \mathrm{NaCl}$ 溶液处理 10 天 后的质膜完整性受到了显著的伤害(图 4(b)中 2),

表 $2700 \mathrm{mmol} / \mathrm{L} \mathrm{NaCl}$ 处理 $24 \mathrm{~h}$ 和 $700 \mathrm{mmol} / \mathrm{L} \mathrm{NaCl}$ 溶液中处理 10 天后未萌发的种子转入去离子水后不同时间的囊果 碱蓬种子光合放氧速率 ${ }^{\text {a) }}$

\begin{tabular}{|c|c|c|c|c|c|}
\hline \multirow{2}{*}{$\mathrm{NaCl} / \mathrm{mmol} \cdot \mathrm{L}^{-1}$} & \multicolumn{3}{|c|}{ 萌发阶段 $/ \mathrm{mmol} \cdot \mathrm{h}^{-1} \cdot \mathrm{L}^{-1}$} & \multicolumn{2}{|c|}{ 恢复萌发阶段/mmol·h ${ }^{-1} \cdot \mathrm{L}^{-1}$} \\
\hline & $0 \mathrm{~h}$ & $6 \mathrm{~h}$ & $24 \mathrm{~h}$ & $0 \mathrm{~h}$ & $24 \mathrm{~h}$ \\
\hline 0 & 0 & $6.24 \pm 0.56$ & $8.21 \pm 1.32$ & - & - \\
\hline 700 & 0 & $6.11 \pm 0.33$ & $7.75 \pm 2.39$ & $5.11 \pm 1.04$ & $10.89 \pm 1.25$ \\
\hline
\end{tabular}

a) 数据为平均值 $\pm \mathrm{SE}, n=3$; 测定时选取 10 粒种子子叶
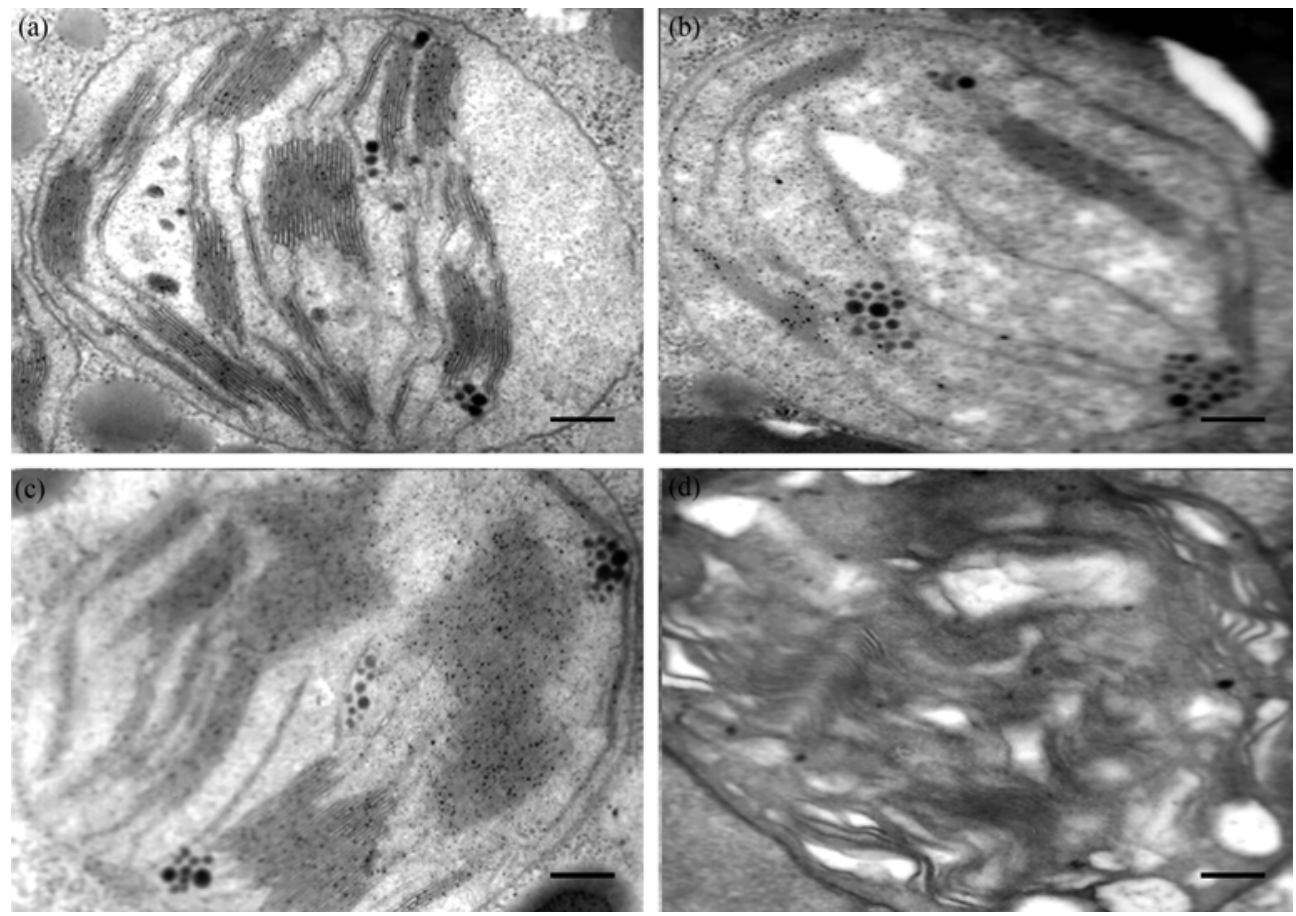

图 3 囊果碱蓬和白梭梭种子分别在 $20^{\circ} \mathrm{C}$ 持续黑暗条件下去离子水中处理 1 天((a)和(c))和 $700 \mathrm{mmol} / \mathrm{L} \mathrm{NaCl}$ 溶液中半浸 没 10 天((b)和(d))后未萌发的子叶叶绿体超微结构 $(\times 21000$, 标尺表示 $400 \mathrm{~nm})$ 
而在去离子水中的种子的胚根没有表现出细胞质膜 受到破坏的迹象(图 4(b)，1). 这表明，真盐生植物囊 果碱蓬种子对高浓度盐害具有很强的抗性.

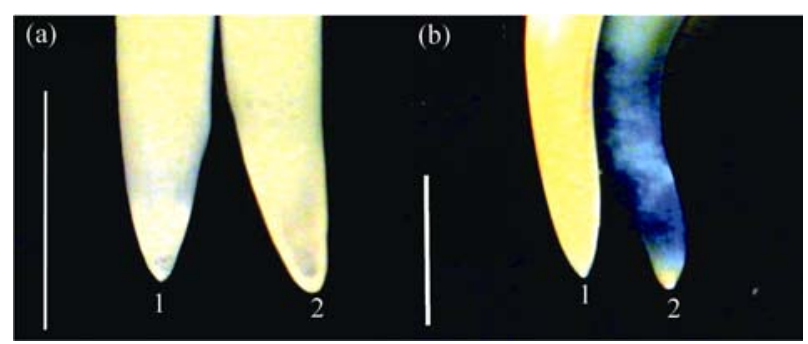

图 4

真盐生植物囊果碱蓬(a)和旱生植物白梭梭(b)种子在 $20^{\circ} \mathrm{C}$ 持续黑暗 条件下去离子水中处理 1 天(图中 1)和 $700 \mathrm{mmol} / \mathrm{L} \mathrm{NaCl}$ 溶液中处 理 10 天(图中 2)胚的 Evan's blue 染料染色. 标尺长度代表 $500 \mu \mathrm{m}$

\section{$2.7 \mathrm{NaCl}$ 处理对囊果碱蓬种子萌发的影响}

囊果碱蓬种子在 $20^{\circ} \mathrm{C}$ 持续黑暗条件下萌发情况 结果如表 3 所示. 结果表明, 与去离子水中的萌发率 相比, 种子在 $700 \mathrm{mmol} / \mathrm{L} \mathrm{NaCl}$ 中的萌发率显著降 低，表明盐分明显抑制了种子萌发，但仍有大约 $30 \%$ 的种子能够萌发. 将 $700 \mathrm{mmol} / \mathrm{L} \mathrm{NaCl}$ 中未萌发的种 子转入去离子水后，其恢复萌发率为 $64 \%$ 左右.

将 $700 \mathrm{mmol} / \mathrm{L} \mathrm{NaCl}$ 处理 10 天末萌发的囊果碱蓬 种子转入去离子水后能够迅速萌发, 当天的恢复萌发 率就达到了 $60 \%$ 以上，对照一般是在第 3 天才达到萌 发最高值(图 5). 经过盐处理以后, 种子不但没有丧失 活力, 条件一旦适宜反而能更加迅速地萌发.

\section{3 讨论}

植物有两种基本抗盐方式，一是忍耐盐害; 二是 躲避盐害. 植物的耐盐性可以通过细胞水平的渗透 调节实现．盐生植物主要是利用无机盐离子进行渗 透调节, 而非盐生植物主要以合成和累积脯氨酸、甜 菜碱及一些糖醇类和有机酸类物质进行渗透调节 $[24]$. 植物逃避盐害的生理机制也有许多种，例如种子在 萌发阶段受到盐胁迫发生休眠，当条件适宜时再萌
发 ${ }^{[24]}$; 通过区隔化使盐分集中于种皮，从而降低萌 发过程中盐对胚的伤害 ${ }^{[10]}$.

叶绿体是对盐害最为敏感的细胞器，易受到盐 胁迫的伤害，盐胁迫对叶绿体超微结构有显著的影 响, 能使其膜系统紊乱和破坏 ${ }^{[25]}$. 研究表明, 生长环 境中的盐浓度达到一定的程度后叶片的类囊体结构 膨胀，基粒排列方向改变，基粒和基质片层界限模糊 不清,最终基粒消失，内膜外膜瓦解，叶绿体也从椭 圆形膨胀成球形 [26, 27]. 本研究结果表明, 与囊果碱 蓬同属僽科的非盐生植物白梭梭, 其种子子叶内也 发现叶绿素 ${ }^{[10]}$, 用 $700 \mathrm{mmol} / \mathrm{L} \mathrm{NaCl}$ 处理 10 天后可以 观察到其种子子叶叶绿体内大部分基粒消失(图 3(c) 和(d)). 而囊果碱蓬种子在 $700 \mathrm{mmol} / \mathrm{L} \mathrm{NaCl}$ 溶液中 处理 10 天后, 其子叶类囊体膜始终保持着完整的形 态结构和膜系统(图 3(a)和(b)). 囊果碱蓬种子在吸收 水分后 $6 \mathrm{~h}$ 就能进行光合作用，经过 $700 \mathrm{mmol} / \mathrm{L} \mathrm{NaCl}$ 高盐度处理 10 天未萌发的种子在移入去离子水后也 立刻能检测到光合放氧作用(表 2). 而且囊果碱蓬种 子子叶中的叶绿素对光的吸收特征曲线在 400 700 $\mathrm{nm}$ 波长范围内与真叶的相同(图 2). 这说明囊果碱蓬 种子子叶所含有的叶绿体, 在种子萌发阶段发生了 与真叶相同的光化学反应, 释放氧气并合成植物早 期生长所需的碳水化合物. 这补充了种子萌发阶段 氧气和光合产物的消耗, 从而加速胚根生长、使幼苗 尽快适应盐渍土壤环境. 根据我们所掌握的资料, 盐 生植物的这种生态生物学特性未曾见到报导.

本研究观察到盐处理降低了种子的萌发率 $(P<0.01)$, 这与以前的研究结果相同 $[10,15]$. 干燥的种 子在去离子水中的萌发过程是渐进式的，萌发率随 时间推延逐渐上升. 值得注意的是，当种子经过了高 盐预处理后，其在去离子水中的复萌则是懪发式的， 在 $24 \mathrm{~h}$ 之内能够萌发的种子就全部迅速萌发了。说明 经过“盐激”的囊果碱蓬种子处于暂时休眠状态而不 萌发，当脱离了盐渍胁迫以后可迅速萌发，构建种

表 $3700 \mathrm{mmol} / \mathrm{L} \mathrm{NaCl}$ 处理对囊果碱蓬种子萌发率、恢复率和计算总萌发率的影响 ${ }^{\text {a) }}$

\begin{tabular}{cccc}
\hline $\mathrm{NaCl} / \mathrm{mmol} \cdot \mathrm{L}^{-1}$ & 萌发率 $/ \%$ & 恢复率 $/ \%$ & 总萌发率 $/ \%$ \\
\hline 0 & $96.0 \pm 0.8 \mathrm{~A}$ & - & $96.0 \pm 0.8 \mathrm{a}$ \\
700 & $31.0 \pm 1.5 \mathrm{~B}$ & $64.0 \pm 4.8$ & $75.0 \pm 1.5 \mathrm{~b}$ \\
\hline
\end{tabular}

a): A, B 表示在 $P=0.01$ 水平差异显著; $\mathrm{a}, \mathrm{b}$ 表示在 $P=0.05$ 水平差异显著 


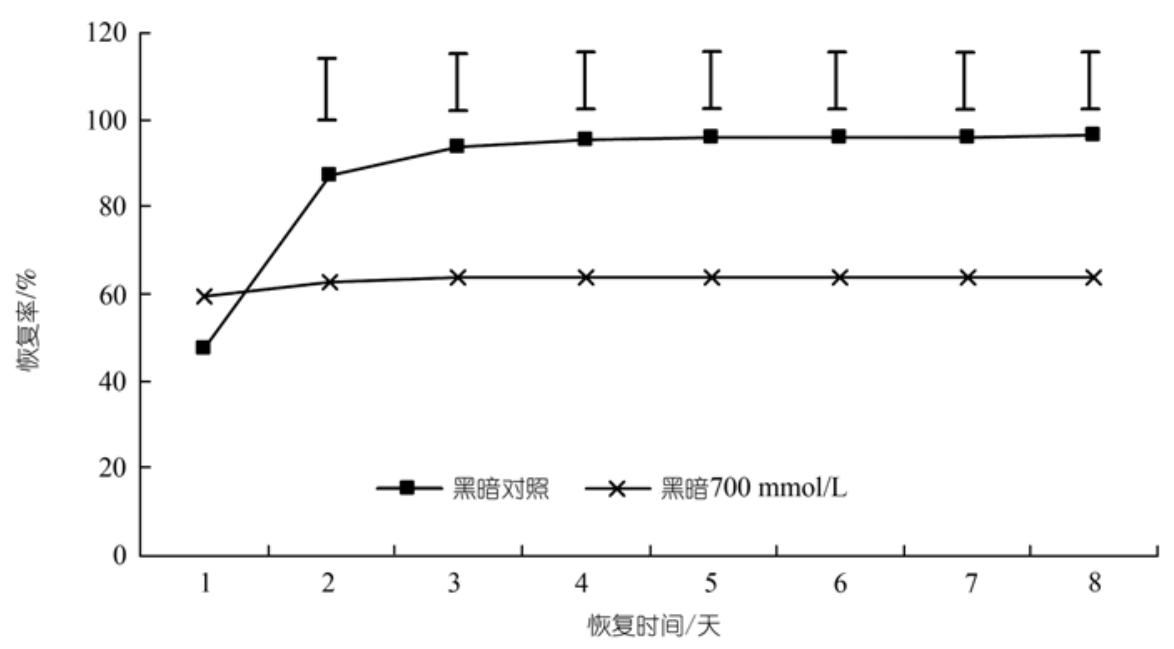

图 5 襄果碱蓬种子在 $20^{\circ} \mathrm{C}$ 持续黑暗条件下 $700 \mathrm{mmol} / \mathrm{L} \mathrm{NaCl}$ 溶液中半浸没 10 天后, 未萌发的种子转移到去离子水 8 天 期间的萌发恢复动态; 图中不同恢复时间所对应的坚线长短代表 LSD0.05 的值

群，这样在一定程度上降低了植株受到高浓度盐的 伤害，甚至致死的风险.

新疆是欧亚大陆最为干燥的地区，其年平均降 水量仅为 $50 \sim 250 \mathrm{~mm}$ ，蒸发潜力高达 1500 3000 mm. 降水少，蒸发强烈，地表容易积盐 ${ }^{[9]}$. 囊果碱蓬种子 库主要集中在土壤表层 $0 \sim 2 \mathrm{~cm}^{[28]}$, 这一土层的土壤 盐分、水分含量变化剧烈. 种子萌发主要集中在每年 的 4 5 月份，这一时期由于春季融雪、洪水和降雨的 淋溶作用, 削减了土壤表层的盐分聚集, 为盐生植物 种子大量萌发提供了短暂的适宜条件 [8]. 本研究证 明，真盐生植物囊果碱蓬具备适应盐渍土条件的生 态生物学特征. 首先, 与其他盐生植物, 如梭梭、灰 绿僽(Chenopodium glaucum)等相比，囊果碱蓬种子在 高盐浓度下有相对较高的萌发率 [29,30]. 其次, 囊果 碱蓬种子子叶中含有叶绿素, 且叶绿体对盐度有较
高的耐性. 经过高盐浓度浸泡的种子，其子叶中叶绿 体结构没有被破坏，仍然保持着光合能力. 第三、脱 水种子吸收水分以后能很快进行光合作用，保证种 子萌发对氧气的需要, 并为萌发出的幼苗早期快速 生长提供光合产物. 第四, 囊果碱蓬种子成熟后脱离 母体，处于盐渍环境中接受“盐分处理”. 经“盐激”处 理的囊果碱蓬种子在水中的萌发速率加快. 这就意 味着自然界中这种植物能够在短暂的低盐度条件下 迅速萌发, 并且借助于子叶光合作用补充的氧气和 碳水化合物快速生长，从而躲避土壤盐分剧烈波动. 这种机制使植物可以在春季短暂的低盐土壤条件下 迅速萌发并建立耐盐机制，以最快的速度度过其生 活史中对盐害最敏感的时期, 保证种群数量的稳定. 关于种子光合作用所合成的碳水化合物对种子快速 萌发和幼苗生长的定量贡献，值得进一步研究.

致谢在新疆野外调查和取样期间得到了中科院新疆生态与地理研究所的张立运研究员的大力帮助，实验 过程中得到段风蒙同学的协助, 在此表示感谢.

\section{参考文献}

1 Thompson K. The functional ecology of seed banks in fennermed seeds. In: Fenner M. ed. The Ecology of Regeneration in Plant Communities. Wallingford: CAB International, 1992, 231-258

2 Lambers J H, Clark J S, Beckage B. Density-dependent mortality and the latitudinal gradient in species diversity. Nature, 2002, 417(13): $732-735$ [DOI]

3 Gutterman Y. Seed Germination in Desert Plants. Berlin: Springer Verlag, 1993. 5-25 
4 Khan M A. Sheith K H. Effects of different levels of salinity on seed germination and growth of Capsicum annuum. Biologia J, 1996, 22: $15-16$

5 Ungar I A. Halophyte seed germination. Bot Rev, 1978, 44: 233-264

6 Levitt J. Reponses of Plants to Environmental Stress. 2nd ed. New York: Academic Press, 1980. 365-434

7 Dodd G L, Donovan L A. Water potential and effects on germination and seedling growth of two cold desert shrubs. Am J Bot, 1999 , 86: $1146-1153$ [DOI]

8 Ball M, Anderson J M. Sensitivity of photosynthesis to $\mathrm{NaCl}$ in relation to the salinity tolerance. Comparative studies with thylakoids of salt-tolerant mangrove, Avicennia marina and the salt-sensitive pea, Pisum sativum. Aust J Plant Physiol, 1986, 13: 689-698

9 魏云杰, 许模. 新疆土壤盐渍化成因及其防治对策研究. 地球与环境, 2005, 33: 593-597

10 宋杰. 内陆干旱区几种盐生植物种子和幼苗抗盐性的研究. 博士学位论文. 北京: 中国农业大学, 2005

11 Khan M A, Ungar I A. Influence of salinity and temperature on the germination of Haloxylon recurvum. Ann. Bot, 1996, 78: 547551 [DOI]

12 朱格麟. 蔡科植物的起源、分化和地理分布. 植物分类学报, 1995, 34(5): 486-504

13 赵可夫, 李法曾. 中国盐生植物. 北京: 科学出版社, 1999

14 Lee J S, Ihm B S. Growth strategies of four salt marsh plants on Manyuan river estuary in Korea. Ecological Res, 2004, 19: 37-42 $\underline{[\mathrm{DOI}]}$

15 王雷, 田长彦, 张道远等。光照、温度和盐分对囊果碱蓬种子萌发的影响.千旱区地理, 2005, 28(5): 670-674

16 Neff M M, Fankhauser C, Chory J. Light: An indicator of time and place. Genes Dev, 2000, 14: 257-271

17 左宝玉, 姜桂珍. 莲胚芽叶绿体在无可见光下的超微结构发育. 植物学报, 1991, 33(3): 169-175

18 邓仲箎 翟波. 红桔种子子叶的叶绿素组成与叶绿体结构的特点. 华中农业大学学报, 1992, 11(4): 327一-332

19 Arnon, D N, Copper enzymes in isolated chloroplasts. Plant Physiol, 1949, 24 (1): 1—-15

20 Yamamoto Y, Kobayashi Y, Matsumoto H. Lipid peroxidation is an early symptom triggered by aluminum, but not the primary cause of elongation inhibition in pea roots. Plant Physiol, 2001, 125: 199-208 [DOI]

21 Grunawdt G, Ehwal R, Goring H. Suitability of the osmotic shock procedure for the analysis of membrane transport in root tips of Zea mays L. J Exp Bot, 1978, 29 (1): 97-106

22 Knopf U C, Bromova M. Electromechanical separation of nuclei representing different phases of the cell cycle from unsynchronized plant cells. Eur J Cell Biol, 1989, 49: 218-220

23 Baker C J, Mock M N. An improved method for monitoring cell death in cell suspension and leaf disc assays using evans blue. Plant Cell Tiss Org Cult, 1994, 39(1): 7-12 $\underline{\text { [DOI] }}$

24 Boscagli A, Sette B. Seed germination enhancement in Sature jamontana L. ssp. montana. Seed Sci Technol, 2001, 29: 347-355

25 Flowers T J, Duque E, Hajibagheri M A, et al. The effect of salinity on leaf ultrastructure and net photosynthesis of two varieties of rice: Further evidence for a cellular component of salt-resistance. New Phytol, 1985, 100(1): 37— 43 [DOI]

26 Goodchild D J, Highkin H R, Boardman N K. The fine structure of chloroplast in a barley mutant lacking chlorophyll b. Exp Cell Res, 1966, 43: 684-688

27 Tanya G F, Janet B M, Andrew S. Severity of mutant phenotype in a series of chlorophyll-deficient wheat mutants depends on light intensity and the severity of the block in chlorophyll synthesis. Plant Physiol, 1996, 112: 821 — 832 [DOD]

28 Irwin A U. Seed banks and seed population dynamics of halophytes. Wetlands Ecol Manage, 2001, 9: 499-510 [DOI]

29 Song J, Feng G, Tian C Y,et al. Strategies for adaptation of Suaeda physophora, Haloxylon ammodendron and Haloxylon persicum to a saline environment during seed-germination stage. Ann Bot, 2005, 96 (3): 399-405 [DOI]

30 Mohammed B, Kinet J M, Lutts S. Osmotic and ionic effects of $\mathrm{NaCl}$ on germination, early seedling growth and ion content of Atriplex halimus (Cheropodiaceae). Can J Bot, 2002, 80 (3): 297-304 [DOI] 